\title{
Platelet-derived growth factor
}

\author{
Isolation by a large-scale procedure and analysis of subunit composition
}

\author{
Carl-Henrik HELDIN,* Bengt WESTERMARK $\dagger$ and Åke WASTESON* \\ *Institute of Medical and Physiological Chemistry, The Biomedical Center, and †The Wallenberg Laboratory, \\ University of Uppsala, S-751 22 Uppsala, Sweden
}

(Received 16 September 1980/Accepted 14 November 1980)

\begin{abstract}
Platelet-derived growth factor was purified from fresh platelets by a large-scale procedure not involving the use of SDS (sodium dodecyl sulphate). The product, $0.5 \mathrm{mg}$ of platelet-derived growth factor, obtained from about $3 \times 10^{13}$ platelets migrated as a single component in analytical gel electrophoresis in the presence of SDS and showed no inhomogeneity on sedimentation-equilibrium analysis in the ultracentrifuge. It had a high specific activity, $2 \mathrm{ng}$ of platelet-derived growth factor $/ \mathrm{ml}(70 \mathrm{pm})$ being equivalent to $1 \%$ (v/v) human serum in an assay for multiplication-stimulating activity. Amino acid analysis revealed that platelet-derived growth factor contains all the common amino acids, except tryptophan, but no hexosamine. The molecular weight of platelet-derived growth factor, as determined by sedimentation-equilibrium analysis, was about 33000 . A similar value was obtained by gel electrophoresis in SDS under non-reducing conditions. In the presence of reducing agents the factor molecule was converted into two distinct components of lower molecular weight (17000 and 14000 respectively), as demonstrated by protein staining. The molecular model implicated by these findings is that platelet-derived growth factor consists of two different polypeptide chains, linked by disulphide bridges.
\end{abstract}

Platelet-derived growth factor (PDGF) is a cationic protein exerting growth-promoting activity on various cultured cells (Ross et al., 1974; Kohler \& Lipton, 1974; Westermark \& Wasteson, 1976; Antoniades \& Scher, 1977); for reviews on PDGF see Ross \& Vogel (1978) and Scher et al. (1979). The purification of PDGF to homogeneity was described from two laboratories (Antoniades et al., 1979; Heldin et al., 1979). Both procedures yielded only small amounts of product (approx. $25 \mu \mathrm{g}$, from 80-200 litres of blood), thus hampering careful investigations on the molecular and biological properties of the factor. Another problem with the available purification protocols is the use of preparative polyacrylamide-gel electrophoresis in SDS as the final step; any SDS remaining bound to PDGF may perturb subsequent analysis. A physical and chemical characterization of PDGF is most important, particularly since conflicting views on the molecular weight of the factor have been presented; the 30000 -dalton value suggested by us (Heldin et al., 1977; 1979) was subsequently

Abbreviations used: PDGF, platelet-derived growth factor; SDS, sodium dodecyl sulphate. questioned by Antoniades et al. (1979). The present investigation was therefore undertaken to improve the procedure for the isolation of PDGF. Large amounts of PDGF ( $500 \mu \mathrm{g}$, from 600 litres of blood) were obtained without the use of SDS; analytical SDS/polyacrylamide-gel electrophoresis indicated that the product was essentially pure. Sedimentation-equilibrium analysis in the ultracentrifuge yielded a molecular weight of about 33000 , thus corroborating the two-chain molecular model for PGDF suggested previously (Heldin et al., 1979).

\section{Materials and methods}

\section{Assay for multiplication-stimulating activity}

Multiplication-stimulating activity was estimated by using the incorporation of $\left[{ }^{3} \mathrm{H}\right]$ thymidine into trichloroacetic acid-precipitable material of serumdeprived sparse cultures of a normal human glial cell line, U-787 CG (Pontén \& Macintyre, 1968) as described by Heldin et al. (1977). Multiplicationstimulating activity was expressed relative to the activity given by medium containing $1 \%(\mathrm{v} / \mathrm{v})$ of a reference serum derived from a pool of healthy human subjects. The reference assay resulted in 
7000-12000 c.p.m. per dish, corresponding to $55-80 \%$ of nuclei labelled as determined by radioautography (Heldin et al., 1977). Controls receiving no multiplication-stimulating activity incorporated $500-2000$ c.p.m. per dish (3-10\% of nuclei labelled).

\section{Purification of PDGF}

Platelet lysate. Platelets were obtained in large quantities through the courtesy of the Finnish Red Cross, Helsinki. Blood collected from healthy donors, with citrate as anticoagulant, was centrifuged at $6400 \mathrm{~g}$ for $4 \mathrm{~min}$. The 'buffy coats' and erythrocytes were removed and used for other purposes. Platelets remaining in the supernatant (about $20-25 \%$ of the total platelets) were pelleted by another centrifugation at $6400 \mathrm{~g}$ for $10 \mathrm{~min}$. The pellets were pooled and stored at $-20^{\circ} \mathrm{C}$ and used as starting material in our purification procedure. Usually platelets from 500 donors (about $10^{13}$ platelets) were processed simultaneously. During the handling, plastic containers or silicone-treated glassware were used to minimize losses of PDGF on vessel walls. After thawing, the platelets were suspended in 2 litres of distilled water $\left(2 \mathrm{ml} / 10^{10}\right.$ platelets) and disintegrated by freezing and thawing five times. Then 1 litre of $1 \mathrm{M}-\mathrm{NaCl} / 0.01 \mathrm{M}$-sodium phosphate buffer, $\mathrm{pH} 7.4$, was added and the suspension centrifuged at $100000 \mathrm{~g}$ for $1 \mathrm{~h}$ at $4^{\circ} \mathrm{C}$. The supernatant was then processed essentially as described by Heldin et al. (1979), by CM-Sephadex chromatography and Blue Sepharose chromatography. All operations were performed at $4^{\circ} \mathrm{C}$, unless otherwise specified.

CM-Sephadex chromatography. The lysate (3 litres, $90 \mathrm{~g}$ of protein) was dialysed against $3 \times 20$ litres of $0.08 \mathrm{M}-\mathrm{NaCl} / 0.01 \mathrm{M}$-phosphate buffer, $\mathrm{pH}$ 7.4. After a small precipitate had been removed by centrifugation at $20000 \mathrm{~g}$ for $20 \mathrm{~min}, 50 \mathrm{~g}$ of dry CM-Sephadex (Pharmacia) was added and the slurry mixed by repeated inversion overnight. The gel beads were then allowed to sediment, the liquid portion was decanted and the remaining slurry poured into a column. After washing with $0.01 \mathrm{M}$ phosphate buffer, pH7.4 $(800 \mathrm{ml})$, the column $(5 \mathrm{~cm} \times 20 \mathrm{~cm})$ was eluted with a linear gradient $(4$ litres) of $0-0.5 \mathrm{M}-\mathrm{NaCl}$ in $0.01 \mathrm{M}$-phosphate buffer, $\mathrm{pH}$ 7.4. Effluent fractions were analysed for protein (Lowry et al., 1951) and multiplication-stimulating activity. Activity was found in both the unadsorbed and the adsorbed fractions. Cationic (adsorbed) PDGF, which was eluted between $0.17 \mathrm{M}$ - and $0.35 \mathrm{M}-\mathrm{NaCl}$ in the gradient, was pooled and used for further purification.

Blue Sepharose chromatography. Cationic PDGF from the CM-Sephadex chromatography $(1300 \mathrm{ml}$; $190 \mathrm{mg}$ of protein) was applied, without prior dialysis, to a $30 \mathrm{ml}(2 \mathrm{~cm} \times 10 \mathrm{~cm})$ column of Blue Sepharose (immobilized Cibacron Blue F3GA;
Pharmacia) at a flow rate of $15 \mathrm{ml} / \mathrm{h}$. The column was washed with about $200 \mathrm{ml}$ of $1 \mathrm{M}-\mathrm{NaCl} / 0.01 \mathrm{M}$ phosphate buffer, $\mathrm{pH} 7.4$, and finally eluted with $60 \mathrm{ml}$ of $50 \%(\mathrm{v} / \mathrm{v})$ ethylene glycol containing $1 \mathrm{M}-\mathrm{NaCl}$ and $0.01 \mathrm{M}$-phosphate buffer, $\mathrm{pH}$ 7.4. A major portion of the multiplication-stimulating activity was recovered in the latter step and used for further purification.

Bio-Gel P-150 chromatography. PDGF purified on Blue Sepharose was dialysed against $1 \mathrm{M}$-acetic acid and freeze-dried. The material ( $9 \mathrm{mg}$ of protein) was dissolved in $3 \mathrm{ml}$ of $1 \mathrm{M}$-acetic acid. A small precipitate was removed by centrifugation; the material was then applied to a column $(2 \mathrm{~cm} \times$ $145 \mathrm{~cm}$ ) of Bio-Gel P-150 (100-200 mesh; Bio-Rad) equilibrated with $1 \mathrm{M}$-acetic acid. Elution was performed at room temperature at a flow rate of $8 \mathrm{ml} / \mathrm{h}$. Effluent fractions were analysed for protein and multiplication-stimulating activity (Fig. 1).

Sephadex G-200 chromatography. Active fractions from three Bio-Gel P-150 chromatographies were pooled as shown in Fig. 1 and freeze-dried. The material $(1.2 \mathrm{mg}$ of protein) was dissolved in $0.8 \mathrm{ml}$ of $1 \mathrm{M}$-acetic acid and applied to a column $(1 \mathrm{~cm} \times$ $145 \mathrm{~cm}$ ) of Sephadex G-200 (fine grade; Pharmacia) equilibrated with $1 \mathrm{M}$-acetic acid. The column was operated at room temperature at a flow rate of $3 \mathrm{ml} / \mathrm{h}$. The effluent was analysed for protein and multiplication-stimulating activity (Fig. 2). PDGF pooled as indicated in Fig. 2 was used in further analyses.

\section{Electrophoresis}

Analytical SDS/polyacrylamide-gel electrophoresis was performed by the method of Laemmli (1970), as described by Heldin et al. (1979), at a gel concentration of $12 \%$ acrylamide. After the run, the gels were stained with Amido Black $(5 \mathrm{~g} / 1$ in $7 \%$ acetic acid) or Coomassie Brilliant Blue R-250 $(2.5 \mathrm{~g} / 1$ in $10 \%$ acetic acid $/ 45 \%$ methanol) and scanned at $570 \mathrm{~nm}$ in a Gilford spectrophotometer 250. Alternatively gels were sliced, extracted and assayed for multiplication-stimulating activity. The molecular-weight markers were as described by Heldin et al. (1979).

\section{Amino acid analysis}

Amino acid analyses were performed in a Beckman $121 \mathrm{M}$ analyser. Samples $(30 \mu \mathrm{g}$ of PDGF per analysis) were hydrolysed in $6 \mathrm{M}-\mathrm{HCl}$ at $110^{\circ} \mathrm{C}$ for $24 \mathrm{~h}$ or $72 \mathrm{~h}$. Values for serine and threonine were obtained by extrapolation to zero time, whereas valine and isoleucine were determined after $72 \mathrm{~h}$ of hydrolysis. Cysteine and methionine were determined after oxidation in performic acid. For tryptophan determinations, samples were hydrolysed in $4 \mathrm{M}$-methanesulphonic acid at $110^{\circ} \mathrm{C}$ for $24 \mathrm{~h}$. 


\section{Ultracentrifugation}

Sedimentation-equilibrium analysis (Chervenka, 1970) was performed in a Beckman model E analytical ultracentrifuge equipped with interference optics. The experiments were performed in capillary-type double-sector cells at a rotor speed of $28000 \mathrm{rev} . / \mathrm{min}$. PDGF purified through the Sephadex G-200 step was freeze-dried and dissolved in $1 \mathrm{M}-\mathrm{NaCl} / 1 \mathrm{M}$-acetic acid. Three different concentrations of PDGF were used: $0.6,0.5$ and $0.3 \mathrm{mg} / \mathrm{ml}$. The partial specific volume of PDGF was calculated from its amino acid composition (Schachman, 1957).

\section{Results}

\section{Purification}

The present procedure for the purification of PDGF from human platelets (Table 1) differs from that previously reported (Heldin et al., 1979) in the following respects: fresh rather than outdated platelets were used, the batch size was increased by a factor of 20 and preparative SDS/polyacrylamidegel electrophoresis was omitted. Although the specific activity of the present platelet lysate from fresh platelets was somewhat lower than that obtained in the previous procedure (Heldin et al., 1979), probably owing to heavy admixture of plasma proteins, a higher specific activity was reached in the CM-Sephadex step. Therefore the use of fresh platelets not only increased the amount of available starting material per platelet, but also led to a more favourable contaminant situation. This was also apparent in the subsequent steps, Blue Sepharose and Bio-Gel P-150 chromatography (Fig. 1), both resulting in higher specific activities than in the previous procedure. The final Sephadex G-200 chromatography was undertaken after combining three individual Bio-Gel P-150 pools to ensure sufficient protein load (Fig. 2). The resulting $540 \mu \mathrm{g}$ of PDGF contained $6 \%$ of the original activity; the potency of this preparation was such that $2 \mathrm{ng} / \mathrm{ml}$ was equivalent to the growth-promoting activity of $1 \%$ human serum (Fig. 3). This specific activity is about twice that obtained with the previous preparation of PDGF (Heldin et al., 1979); however, the discrepancy is probably due to uncertainty in the determination of the protein concentration of the latter preparation. The recovery of PDGF (about 6\%) may appear low, but compares favourably with that reported previously (Antoniades et al., 1979; Heldin et al., 1979). Each individual step showed a total recovery (before pooling) of $65 \%$ or better. It should also be noted that the biological activity of the starting material, on which the calculation of recovery was based, included anionic material with a distinct growth-promoting activity (Heldin et al., 1979); therefore the recovery of cationic PDGF was about twice that indicated in Table 1.

\section{Electrophoresis}

Gel electrophoresis of PDGF in the presence of SDS revealed the presence of a single Amido Black-stainable band, with migration properties conforming to those of a 30000 -dalton protein (Fig. 4). Coomassie Blue staining, being less suitable for quantification by scanning but more sensitive, yielded only minor additional components (results not shown). The biological activity of the preparation showed, as expected, an identical mobility, as demonstrated with a parallel gel assayed for multiplication-stimulating activity after slicing and extraction. Under reducing conditions, known to

Table 1. Purification of PDGF from fresh platelets

Human blood from 500 donors (i.e. 200 litres) was used for the preparation of platelets as described in the Materials and methods section. The resulting platelet lysate derived from about $10^{13}$ platelets. The results represent mean values for six individual preparations.

$\begin{array}{lccc}\text { Stage } & \begin{array}{c}\text { Total protein } \\ (\mathrm{mg})\end{array} & \begin{array}{c}\text { Recovery } \\ \text { of activity } \\ (\%)\end{array} & \begin{array}{c}\text { Protein conen. } \\ \text { equivalent to } \\ \text { 1\% human serum } \\ (\mathrm{ng} / \mathrm{ml})\end{array} \\ \text { Human serum } & & 100 & 700000 \\ \text { Platelet lysate } & 90000 & 30 & 50000 \\ \text { CM-Sephadex } & 190 & 20 & 330 \\ \text { Blue Sepharose } & 9 & 9 & 25 \\ \text { Bio-Gel P-150 } & 0.4 & 6 & 3 \\ \text { Sephadex G-200 } & 0.18^{*} & 6 & 2\end{array}$

* This value is based on a batch size of 500 units of blood (each $400 \mathrm{ml}$ ). In practice three individual batches were combined after the Bio-Gel P-150 step, resulting in about $540 \mu \mathrm{g}(3 \times 180 \mu \mathrm{g})$ of PDGF in the Sephadex G-200 chromatography. 


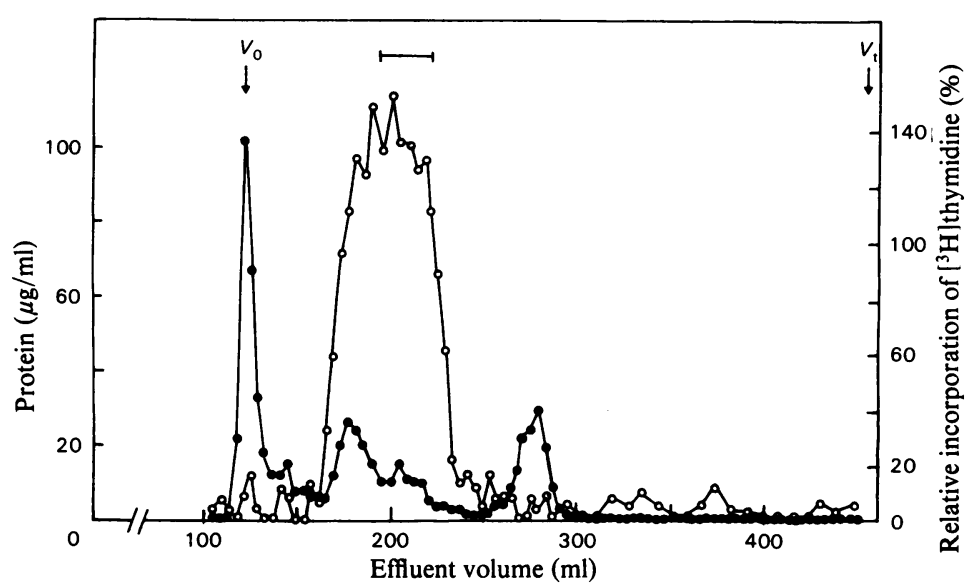

Fig. 1. Chromatography on Bio-Gel P-150 in $1 \mathrm{M}$-acetic acid of PDGF purified on Blue Sepharose

A $9 \mathrm{mg}$ sample of protein was applied to a $2 \mathrm{~cm} \times 145 \mathrm{~cm}$ column. Effluent fractions were analysed for protein (๑) and multiplication-stimulating activity (O). In the latter assay samples were tested at a final dilution of $1: 2500$ and the result was expressed as percentage of the activity given by $1 \%$ human serum (see the Materials and methods section). Note that the concentration of biological activity in the most active fractions yielded maximal stimulation in the assay. This contributes to the width of the peak of biological activity. Fractions were pooled as indicated. The void volume $\left(V_{0}\right)$ and the total volume $\left(V_{t}\right)$ of the column are indicated by arrows.

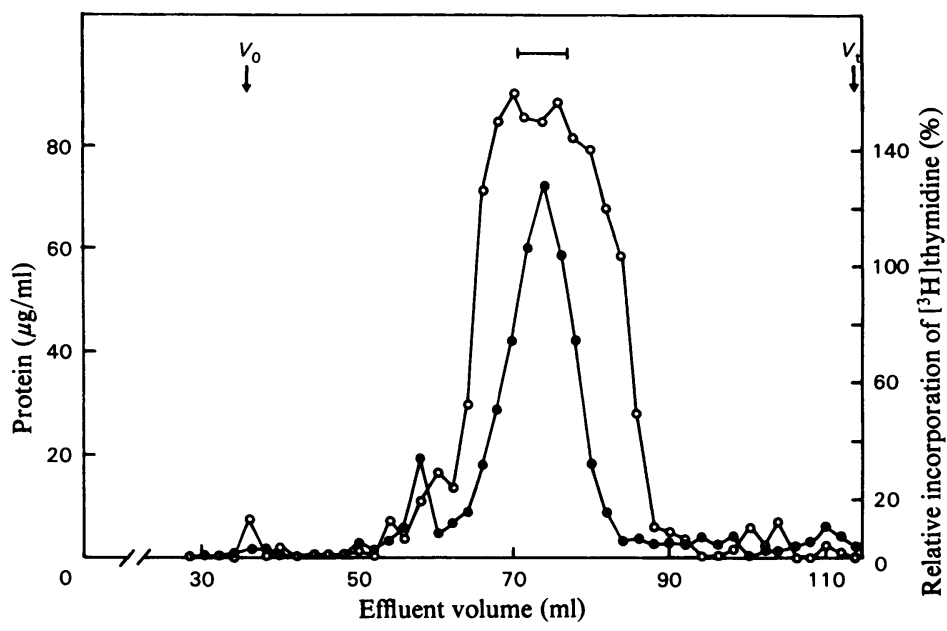

Fig. 2. Chromatography on Sephadex G-200 in $1 \mathrm{M}$-acetic acid of PDGF pooled from three individual Bio-Gel P-150 chromatographies (Fig. 1)

A $1.2 \mathrm{mg}$ sample of protein was applied to a $1 \mathrm{~cm} \times 145 \mathrm{~cm}$ column. The effluent was analysed for protein $(0)$ and multiplication-stimulating activity (O). In the latter assay, samples were tested at a final dilution of $1: 2500$ and the result was expressed as described in the legend to Fig. 1 (see also the comments in the legend to Fig. 1). The three most active fractions were pooled as indicated.

destroy the biological activity, the 30000-dalton component disappeared, giving rise to two fastermoving bands, with mol.wts. 17000 and 14000 respectively.

\section{Amino acid analysis}

Amino acid analysis indicated that PDGF contained all the common amino acids except trypto- 


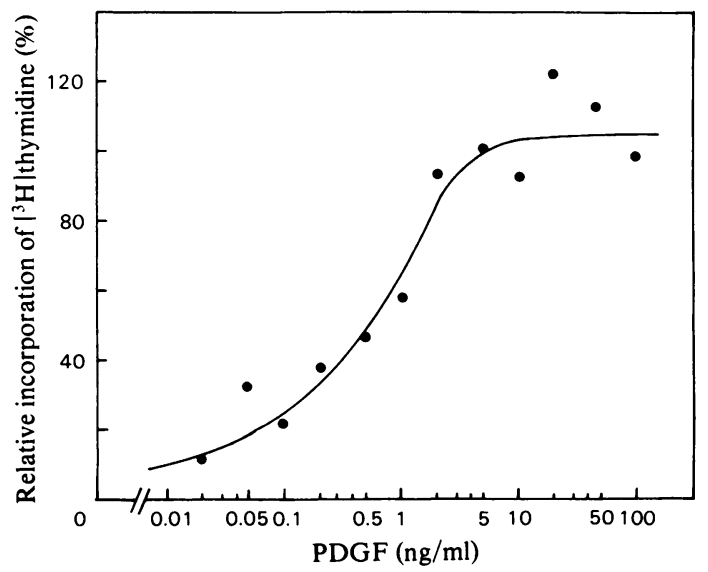

Fig. 3. Dose-dependent biological activity of purified $P D G F$

The multiplication-stimulating activity (expressed as described in the legend to Fig. 1) was recorded as a function of the concentration of PDGF, purified as described in Table 1.

Table 2. Amino acid composition of PDGF The results are based on analyses of three different preparations. Cysteine, methionine and tryptophan were determined separately as described in the Materials and methods section. The number of residues of individual amino acids was calculated by assuming a molecular weight of 32700 .

\begin{tabular}{ccc} 
& \multicolumn{2}{c}{ Content } \\
\cline { 2 - 3 } Amino acid & $\begin{array}{c}\text { No. of residues } \\
\text { per } 100 \text { amino acids }\end{array}$ & $\begin{array}{c}\text { No. of residues } \\
\text { per PDGF molecule }\end{array}$ \\
Lys & 8.9 & 26.1 \\
His & 2.5 & 7.3 \\
Arg & 7.5 & 21.9 \\
Asx & 7.9 & 23.1 \\
Thr & 6.3 & 18.5 \\
Ser & 5.1 & 15.0 \\
Glx & 12.7 & 37.1 \\
Pro & 5.6 & 16.5 \\
Gly & 5.4 & 15.8 \\
Ala & 7.6 & 22.3 \\
Cys & 3.7 & 10.9 \\
Val & 9.1 & 26.5 \\
Met & 1.0 & 3.0 \\
Ile & 4.9 & 14.5 \\
Leu & 7.2 & 21.3 \\
Tyr & 1.7 & 5.0 \\
Phe & 2.9 & 0 \\
Trp & 0 & 0 \\
GlcN & 0 & 0 \\
GalN & 0 & 293 \\
& 100.0 &
\end{tabular}

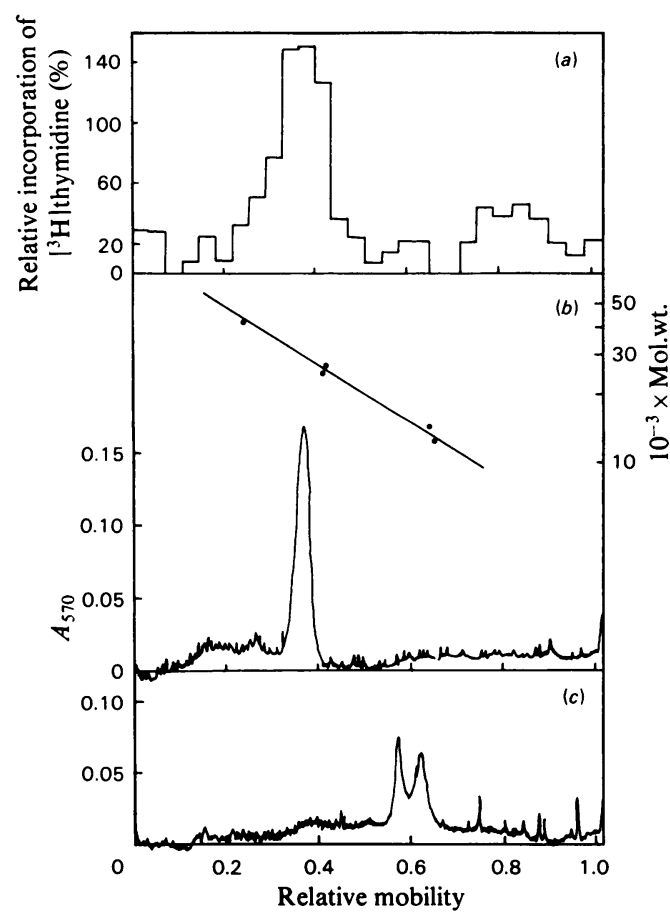

Fig. 4. SDS/polyacrylamide-gel electrophoresis of PDGF (a), PGDF $(10 \mu \mathrm{g})$, purified as in Table 1 , was run under non-reducing conditions and assayed for multiplication-stimulating activity (expressed as described in the legend to Fig. 1). Gels were sliced in $4 \mathrm{~mm}$-wide pieces; each slice was extracted with $1.0 \mathrm{ml}$ of $0.15 \mathrm{M}-\mathrm{NaCl} / 0.01 \mathrm{M}$-sodium phosphate $(\mathrm{pH} 7.4) / 0.02 \% \mathrm{SDS}$ for $20 \mathrm{~h}$ at $4^{\circ} \mathrm{C}$. Extracts were assayed at a final dilution of $1: 500$. (See also the comments in the legend to Fig. 1.) (b), Unreduced PDGF $(10 \mu \mathrm{g})$ and $(c)$ reduced PDGF $(20 \mu \mathrm{g})$ were run on gels which were then stained for protein with Amido Black and scanned at $570 \mathrm{~nm}$. The mobilities of reduced standard proteins are indicated $(\boldsymbol{O})$. The anode is to the right.

phan (Table 2). The partial specific volume of PDGF, calculated from its amino acid composition, was $0.737 \mathrm{ml} / \mathrm{g}$. The absence of hexosamine suggests that PDGF is not a glycoprotein.

\section{Ultracentrifugation}

Sedimentation-equilibrium analysis of PDGF in $1 \mathrm{M}$-acetic acid/1 $\mathrm{M}-\mathrm{NaCl}$ indicated homogeneity and yielded similar molecular weights (mean 32700 daltons) at three different concentrations (Fig. 5). Acetic acid was included in the solvent to enhance the solubility of PDGF at the relatively high concentrations used. Omitting $1 \mathrm{M}-\mathrm{NaCl}$ from the solvent led to a concentration-dependent behaviour

Vol. 193 


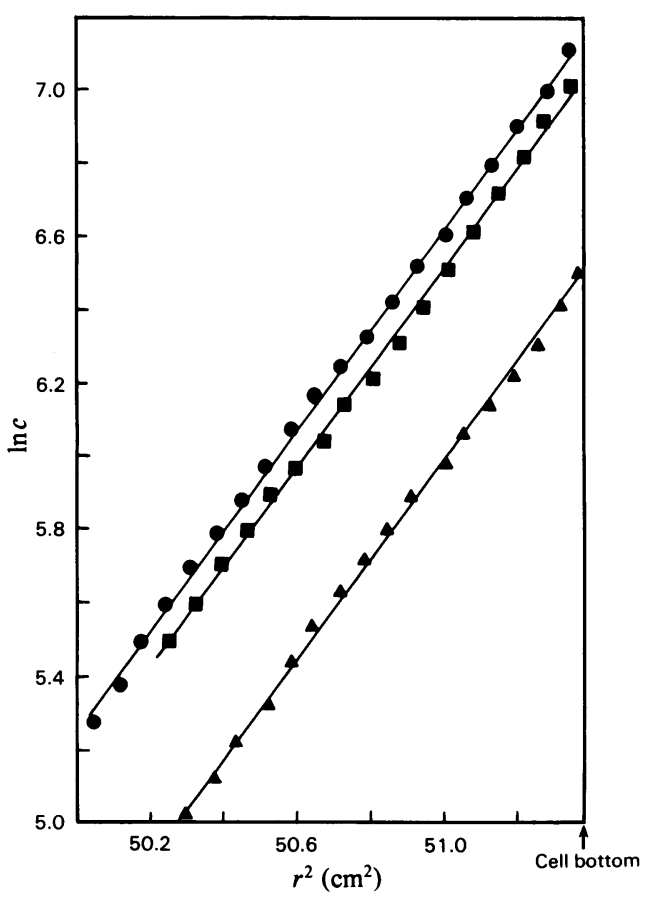

Fig. 5. Sedimentation-equilibrium analysis of PDGF Ultracentrifugation was performed at three different concentrations $(0,0.6 \mathrm{mg} / \mathrm{ml} ; \square, 0.5 \mathrm{mg} / \mathrm{ml} ; \Delta$, $0.3 \mathrm{mg} / \mathrm{ml}$ ) in $1 \mathrm{M}-\mathrm{NaCl} / 1 \mathrm{M}$-acetic acid. The concentration, expressed as $\ln$ fringe displacement $(c)$, was plotted versus the square of the distance from the rotor axis $(r)$.

of PDGF, probably owing to charge effects of the strongly cationic protein.

\section{Discussion}

We have previously suggested that the molecular weight of unreduced PDGF is about 30000 . This value was based on the migration of PDGF in polyacrylamide-gel electrophoresis in the presence of SDS (Heldin et al., 1977, 1979). It may be argued that, since a cationic unreduced protein may bind proportionally less SDS than do standard proteins (Weber \& Osborn, 1975), the molecular weight of PDGF may have been overestimated in this analytical system. The analysis of PDGF in the reduced form was only performed with ${ }^{125} \mathrm{I}$-labelled PDGF; the available amounts of material were so small that the migration of the reduction products could not be satisfactorily determined by protein staining. Antoniades et al. (1979) obtained essentially confirmatory data, finding a mobility of unreduced biologically active PDGF corresponding to a molecular weight of 35000-38000. However, these authors were inclined to have more confidence in a much lower molecular-weight value, 13000-16000, obtained by chromatography of PDGF on Bio-Gel P-150 in the presence of $1 \mathrm{M}$-acetic acid and by SDS/polyacrylamide-gel electrophoresis performed under reducing conditions. To solve this controversy, we considered it necessary to prepare sufficient amounts of PDGF to permit an independent physical-chemical analysis. From large amounts of fresh platelets about $0.5 \mathrm{mg}$ of PDGF was obtained. In contrast with previous preparations (Antoniades et al., 1979; Heldin et al., 1979), this material had not been exposed to SDS. A single band was observed in analytical SDS/polyacrylamide-gel electrophoresis under non-reducing conditions (Fig. 4); also no inhomogeneity was detectable by ultracentrifugation (Fig. 5). Sedimentation-equilibrium analysis resulted in a molecular weight of about 33000 , in accordance with values obtained by SDS/polyacrylamide-gel electrophoresis. Moreover, reduction of PDGF produced two distinct stainable components with moelcular weights 17000 and 14000 (Fig. 4). The molecular model implicated by these findings is that PDGF is composed of two different polypeptide chains, covalently linked to make up a total molecular weight of slightly more than 30000 . Disulphide bridges are probably involved in the assembly of the PDGF molecule, since, along with the formation of the two polypeptide chains on reduction, the biological activity is irreversibly destroyed, whereas under non-reducing conditions the biological activity is highly stable to denaturing agents. Amino acid analysis indicated that enough half-cystine residues were present to account for five disulphide bridges. The relation between the two constituent chains is not known; one may speculate that they have been formed by proteolytic cleavage of a single-chain precursor molecule. Such a modification may either be a specific event in the life cycle of PDGF (e.g. activation) or be a non-specific but limited degradation during the preparation.

We thank F. Carlsson, M. Kastemar and A. Magnusson for excellent technical assistance, L. Nirk for performing the amino acid analyses and Dr. H. Pertoft for performing the ultracentrifugations. Thanks are also due to the Finnish Red Cross, Helsinki, for the generous supply of platelets. This work was supported by grants from the Swedish Cancer Society (55 and 689), the Swedish Medical Research Council (4486 and 03X-4) and the University of Uppsala.

\section{References}

Antoniades, H. N. \& Scher, C. D. (1977) Proc. Natl. Acad. Sci. U.S.A. 74, 1973-1977

Antoniades, H. N., Scher, C. D. \& Stiles, C. D. (1979) Proc. Natl. Acad. Sci. U.S.A. 76, 1809-1813

Chervenka, C. H. (1970) Anal. Biochem. 34, 24-29 
Heldin, C.-H., Wasteson, Å. \& Westermark, B. (1977) Exp. Cell Res. 109, 429-437

Heldin, C.-H., Westermark, B. \& Wasteson, A. (1979) Proc. Natl. Acad. Sci. U.S.A. 76, 3722-3726

Kohler, N. \& Lipton, A. (1974) Exp. Cell Res. 87, 297-301

Laemmli, U. K. (1970) Nature (London) 227, 680-685

Lowry, O. H., Rosebrough, N. J., Farr, A. L. \& Randall, R. J. (1951) J. Biol. Chem. 193, 265-275

Pontén, J. \& Macintyre, E. M. (1968) Acta Pathol. Microbiol. Scand. 74, 465-486
Ross, R. \& Vogel, A. (1978) Cell 14, 203-210

Ross, R., Glomset, J., Kariya, B. \& Harker, L. (1974) Proc. Natl. Acad. Sci. U.S.A. 71, 1207-1210

Schachman, H. K. (1957) Methods Enzymol. 4, 32-103

Scher, C. D., Shepard, R. C., Antoniades, H. N. \& Stiles, C. D. (1979) Biochim. Biophys. Acta 560, 217-241

Weber, K. \& Osborn, M. (1975) in The Proteins (Neurath, H. \& Hill, R. L., eds.), vol. 1, pp. 179-223, Academic Press, New York

Westermark, B. \& Wasteson, A. (1976) Exp. Cell Res. 98, $170-174$ 